EXTENDED REPORT

\title{
Cut and paste: a no suture, small incision approach to pterygium surgery
}

\author{
G Koranyi, S Seregard, E D Kopp
}

Br J Ophthalmol 2004;88:911-914. doi: 10.1136/bjo.2003.032854

See end of article for authors' affiliations

.....................

Correspondence to: Gabor Koranyi, MD, St

Erik's Eye Hospital, 11282

Stockholm, Sweden;

gabor.koranyi@

sankterik.se

Accepted for publication 30 November 2003

\begin{abstract}
Aim: Evaluation of the benefits of a new technique for pterygium surgery with respect to postoperative pain and surgery time.

Methods: A prospective randomised clinical trial was carried out in 43 patients. 43 eyes were operated for primary nasal pterygium. Autologous conjunctival graft taken at the superotemporal limbus was used to cover the sclera after pterygium excision. After randomisation, in 20 patients the transplant was attached to the sclera with a fibrin tissue adhesive (Tisseel Duo Quick) and in 23 patients with absorbable sutures (7-0 Vicryl Rapid). The Mann-Whitney test was used as statistical analysis. Postoperative pain was graded according to the visual analogue scale (VAS) twice daily during the first week after surgery. Surgery time was noted from the first incision until the lid speculum was removed.

Results: The average pain was significantly lower when glue had been used, $p<0.05$. Average surgery time was 9.7 minutes (range 6-13) for glue and 18.5 minutes (range 12-30) for sutures, $p<0.001$. No complications occurred.

Conclusion: Using glue instead of sutures when attaching the conjunctival transplant in pterygium surgery causes significantly less postoperative pain and shortens surgery time significantly.
\end{abstract}

$P$ terygium is a wing shaped conjunctival encroachment onto the cornea generally situated on the nasal side. It sometimes occurs both nasally and temporally, and rarely only on the temporal side. Pterygium is more frequent in areas with more ultraviolet radiation, ${ }^{1}$ in hot, dry, windy, dusty, and smoky environments. ${ }^{2}{ }^{3}$ There is also a hereditary factor. ${ }^{4}$ During the past decade numerous authors have been interested in corneal stem cells. These are situated in the deeper layers at the limbus according to Tseng and coworkers. When deeper parts of the limbal epithelium is damaged or removed, an abnormal corneal surface is produced. The characteristic changes are conjunctival epithelial ingrowth, vascularisation, inflammation. These signs are also seen in pterygia; thus the authors speculate that pterygium manifests limbal deficiency. Anti-inflammatory drugs and lubricants have an important role minimising the patients' discomfort but do not cure the disease. Ablation with erbium:YAG laser ${ }^{5}$ and smoothing the corneal surface with excimer laser ${ }^{6}$ have been tried but the results were not encouraging.

Surgical removal is the treatment of choice. Many techniques have been suggested, as have adjunct therapies such as $\beta$ radiation, thiotepa, 5-FU, and mitomycin C. High recurrence rates are weighted against eye threatening postoperative complications. Autologous conjunctival grafting seems to be the best method, giving both low recurrence rate and high safety..$^{7-9}$ The recurrence in most cases is seen within 6 months, but can sometimes occur later. ${ }^{10}$ Our objective was to lessen patient discomfort by using glue rather than sutures when securing the graft.

Tisseel Duo Quick (Baxter, Vienna, Austria) is a two component tissue adhesive which mimics the natural fibrin formation. It has been used in neurosurgery, plastic surgery, ENT, and ocular surgery. This glue has two components. One consists of fibrinogen mixed with factor XIII and aprotinin. The other component is a thrombin- $\mathrm{CaCl}_{2}$ solution. All components are prepared from banked and well controlled human blood. Equal amounts of the components are mixed together. Through the action of thrombin, the fibrinopeptides are split to fibrin monomers. These monomers aggregate by cross linking, resulting in a fibrin clot. Thrombin concentration can be varied to regulate the speed of coagulation. Low thrombin concentrations $(4 \mathrm{NIH}-\mathrm{U} / \mathrm{ml})$ with slow clotting are used, for example, in skin grafting while high thrombin concentrations $(500 \mathrm{NIH}-\mathrm{U} / \mathrm{ml})$ are beneficial where almost instantaneous clotting is desired. The double syringe applicator (Duploject) is usually advocated for mixing, in order to obtain precise amounts of the components. However, the sealant can be applied sequentially or premixed through needles, spraying heads, or catheters. The glue does not stick to intact corneal or conjunctival epithelium. ${ }^{1}$

In ocular surgery sealing perforations in the lens capsule, treating conjunctival wounds and fistulas, adapting free skin transplant in lid surgery, repairing injured canaliculi and sealing the wound in cataract surgery are described. ${ }^{12-14}$ We could find only one report of its application in pterygium surgery ${ }^{15}$ : six conjunctival transplants were both glued and sutured to ensure graft adhesion.

There is very little reported on postoperative pain and operation time in pterygium surgery. Wishaw and coworkers compared different analgesic methods. ${ }^{16}$ We found no references regarding postoperative pain and surgery time when comparing different methods in pterygium surgery. In this study we present a new method, where autologous conjunctival graft was glued on the sclera and we compare the results with those obtained with sutured grafts. Outcome measures were, in addition to success of the surgical procedure, postoperative pain and surgical time.

\section{MATERIAL AND METHODS}

A randomised prospective clinical trial was designed to compare the pain and the surgery time for sutured and for glued autologous conjunctival transplants in pterygium surgery. The study was approved by the local ethics committee at Karolinska Institute and conducted from February to April 2000.

Patients referred to our hospital for pterygium surgery were enrolled in the study if they had a nasal primary pterygium 
and if informed consent was obtained. Power calculations with a type I error of 0.05 and type II error of 0.8 were executed. Assuming that the success proportion of the groups were $25 \%$ and $75 \%$ respectively, we needed to have 13 patients in each group. Forty three eyes of 43 patients were randomised by a computer random function into two groups. In 20 patients we used glue and in 23 patients sutures to secure the transplants. The sutures used in this study were 7-0 Vicryl Rapid (Ethicon, Johnson \& Johnson, Brussels, Belgium). The reasons for this are discussed later.

The male/female distribution was $65 \% / 35 \%$ in the glue group and $55 \% / 45 \%$ in the suture group. The mean age was 44 (SD 14, range 23-78) years in the glue group and 48 (16, range 26-78) years in the suture group.

One surgeon (GK) performed all preoperative investigations, surgical procedures, and postoperative evaluations.

Before the surgery amethocaine (tetracaine) eye drops (AME 1.0\%, Chauvin Pharm Ltd, Essex) were given three times. The pain after the first drop of amethocaine was evaluated using the visual analogue scale (VAS), and the patient was instructed how to use the VAS during the postoperative week. VAS is a simple scale, consists of a $10 \mathrm{~cm}$ line anchored at one end by a label "no pain" and at the other end by "worst possible pain." The patient marks on the line how severe the pain is at the moment. On the back, the scale is transformed to numerical values from 0 to 100 for statistical analysis. The initial VAS value was used later as a reference pain level for each patient and subtracted from all postoperative VAS values obtained from this patient. The surgery was performed using an operation microscope. Lidocaine $0.2-0.5 \mathrm{ml}$ with adrenaline (epinephrine) (Xylocaine $20 \mathrm{mg} / \mathrm{ml}$ + adrenaline $12.5 \mu \mathrm{g} / \mathrm{ml}$, Astra, Södertälje, Sweden) was given subconjunctivally beneath the pterygium body along with further topical administration of the same solution when necessary.

The adhesion between the pterygium and the sclera was sharply incised at the limbus and the pterygium head was separated from the cornea by blunt dissection with use of an iris spatula (fig 1). Only the thickened and keratinised portions of the conjunctiva and the underlying Tenon's capsule were excised. The wound bed was scraped to clean cornea and sclera and only bleeding vessels were cauterised. No extensive excision of the surrounding subconjunctival Tenon's capsule was done (fig 2).

A free conjunctival graft of the same size as the nasal conjunctival defect was prepared at the superotemporal limbus of the same eye (fig 2). Care was taken to include as little as possible of Tenon's tissue on the graft. The limbal edge of the graft was cut to contain a thin rim of corneal epithelium. The graft was thereafter moved to the nasal area

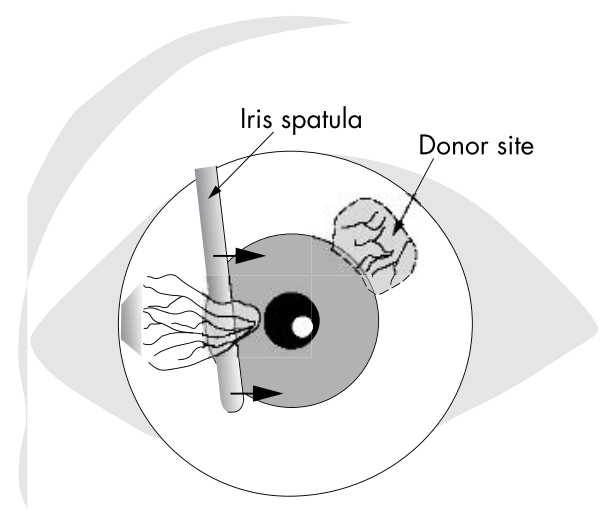

Figure 1 Blunt dissection of the pterygium head. Autotransplant is marked at the superotemporal limbus.

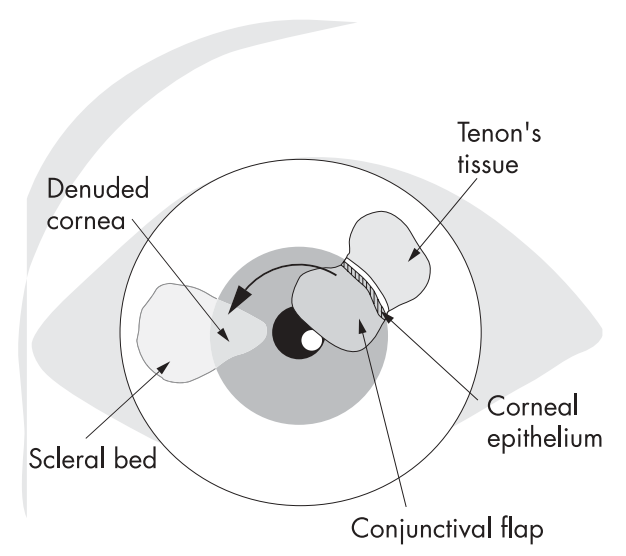

Figure 2 Pterygium is excised. The conjunctival transplant is prepared lying upside down on the cornea.

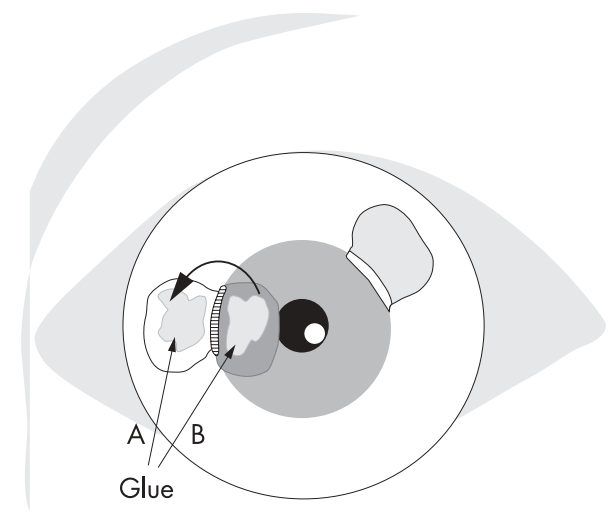

Figure 3 The conjunctival graft is slid nasally with the limbal edge facing towards the limbus. One drop of the thrombin solution $(A)$ and one drop of the protein solution (B) are placed.

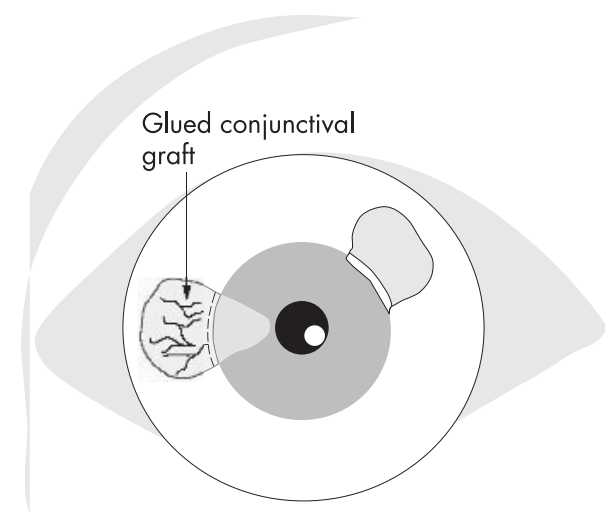

Figure 4 The graft is flipped over and glued.

and attached to the sclera either with sutures or with glue. Proper orientation was maintained, with the epithelium side up and the limbal edge towards the limbus.

When operating patients in the suture group, the graft was placed with the epithelium side up onto a paper template from the suture cover before being cut off at the limbus according to the technique of Shaw. ${ }^{17}$ This method allows easy handling and proper orientation of the graft. The corners of the graft were anchored to the sclera at the limbus. The rest of the circumference was attached to the nasal conjunctiva running sutures. The knots were not buried. 


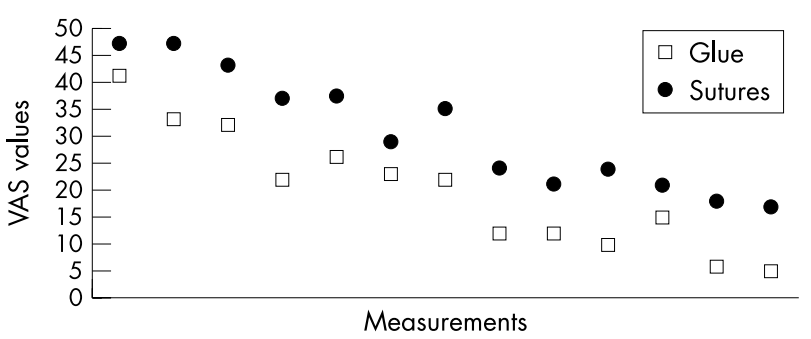

Figure 5 Medians of postoperative VAS values in the glue and the suture group monitored twice daily.

When glue was used, the graft was placed with the epithelium side down on the cornea (fig 2). It was slid carefully to the nasal side with the limbal edge facing towards the wound. One drop of the thrombin component was placed on the scleral bed and one drop of the protein solution was put onto the graft (fig 3). Thereafter, the graft was quickly flipped over to the sclera and smoothed out while the fibrinogen was activated by the thrombin, forming the fibrin glue (fig 4). After the graft was positioned, there was about 30 seconds to smooth out the graft and press it gently to the scleral bed, attaching the graft firmly but not stiffly. Excess glue was removed and the graft was trimmed if necessary. Surgery time was monitored and noted from the first incision to the removal of the lid speculum.

No patching or bandage contact lenses were used. Rimexolone (Vexol, Alcon Lab Inc, Forth Worth, TX, USA) eye drops six times daily, tapered out during 6 weeks, and chloramphenicol ointment (Chloromycetin, Parke-Davis, Stockholm, Sweden) twice daily for 1 week were prescribed. Rimexolone was chosen for its low inclination to cause elevation in intraocular pressure. ${ }^{18}$

The patients were asked to fill out a questionnaire with copies of the VAS on the evening of the operation day and then twice daily during 1 week until the first postoperative check up.

At day 7, all sutures were removed in the suture group. VAS figures were adjusted individually according to the reference level obtained for each patient preoperatively to avoid possible differences in pain thresholds. Pain values and surgery times were evaluated using the Mann-Whitney U test as statistical analysis.

\section{RESULTS}

One patient in the suture group was withdrawn because of inability to fill out the VAS questionnaire.

The medians of the VAS values at each measurement occasion are shown (fig 5). After adjusting for individual pain sensitivity we found significantly lower pain levels in the glue group both on day 0 , and at each point of time during the first postoperative week, $\mathrm{p}<0.05$ (fig 6).

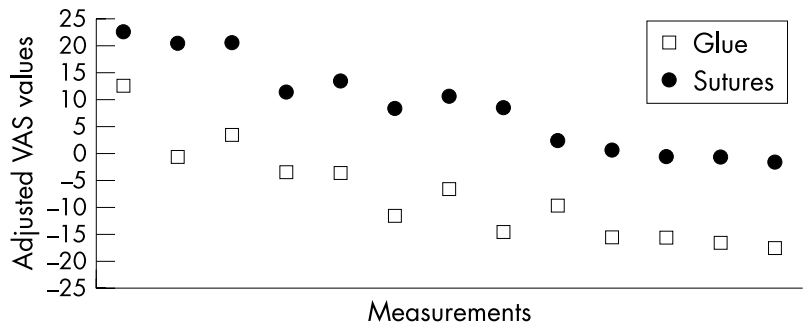

Figure 6 Medians of the adjusted postoperative VAS values. Glue and suture group monitored twice daily. At each point of time $p<0.05$ (Mann-Whitney U test).
Median surgery time was 10 minutes (range 6-13) in the glue group and 17 minutes (range 12-30) in the suture group, $\mathrm{p}<0.001$ (fig 7 ). The surgery times sorted in date order did not indicate any learning curve (data not shown). Regression analysis was performed between pterygium size and postoperative pain as well as between pterygium size and surgery time. Any correlations were not found (data not shown).

There were no transplant losses or dislocations. Neither transplant necroses nor excessive postoperative bleeding were seen. A yellowish transplant oedema was sometimes observed and was slightly more common in the glue group. This resolved later, spontaneously. Any elevations of the intraocular pressure were not observed. No side effects of the Tisseel were noted. Two recurrences in the glue group (8\%) and four in the suture group (20\%) were seen within 6 months' follow up. They occurred after 2-3 months. No reoperations have been necessary. The recurrences will be followed.

The transplants healed with excellent cosmetic result. The donor sites healed in every case without any problems.

\section{DISCUSSION}

There have been many attempts to optimise pterygium surgery. Today, a wide variety of techniques are in use, from the bare sclera procedure without using a microscope to very complex approaches like amniotic membrane transplantation $^{9}$ and lamellar keratoplasty. ${ }^{19}$ The aim is to excise the pterygium and prevent its recurrence. Authors describing their surgical technique usually report only the method and the recurrence rate after different lengths of follow up, and sometimes the complications, especially if they are serious. Autologous conjunctival transplantation avoids the risk of scleral necrosis associated with the alternative adjunctive therapies at the cost of increased surgical time and early postoperative discomfort. ${ }^{20}$

The cut and paste method described here was developed to address patient discomfort, especially postoperative pain and surgical time. In addition, postoperative patching, healing time and restrictions in normal life after surgery were of concern.

Evaluating pain is not easy. Patients report different sensitivity for the same stimulus. In addition, they have different capacity to withstand the pain. Furthermore, they have different ability to report their experience. In this study, the patients did not know whether the sutures or the glue would cause more pain. They received exactly the same preoperative information from the same person. We believe that adjusting the VAS values by subtracting the value after a uniform stimulus gives us a fair possibility to compare pain measurements. In this paper we have shown that the use of a fibrin tissue adhesive when securing the autologous conjunctival graft in pterygium surgery causes significantly less

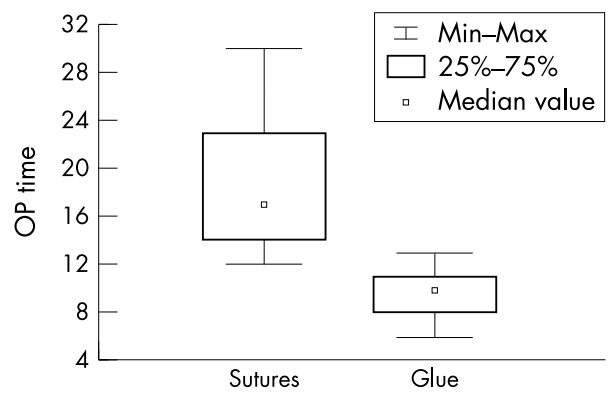

Figure 7 Box plot of surgery times in minutes. Medians, quartiles, minimum, and maximum values for each group are shown. The difference is significant, $p<0.001$ (Mann-Whitney). 
pain than using sutures. For suturing, several materials and techniques are in use-Vicryl, nylon, catgut in different dimensions, interrupted or/and running, buried or not buried knots. During previous years, when suturing the conjunctival transplant, we have tried interrupted and running 7-0 Vicryl and Vicryl Rapid, 8-0 Vicryl, 10-0 nylon, also with buried knots. We did not experience any major difference in pain sensation. On the other hand patients reported remarkably little pain, when we started with glue. Removal of the stitches, especially the buried knots was a great problem for many patients. This caused considerable extra effort in time, and additional pain to them. Of the absorbable sutures 7-0 Vicryl Rapid dissolves fastest and, in addition, it softens markedly during the first day, causing less pain than other sutures. For these reasons this suture became our preferred choice, and it seemed natural to use it for the study.

Surgery time was also significantly shorter. This method entails excision of a smaller amount tissue and thus smaller grafts, which leads to faster healing and less inflammation and pain. Excising only a small amount of conjunctiva is essential in this method as is the blunt dissection of the pterygium head. The flipover manoeuvre leaves a thin membrane of glue on the corneal epithelial defect. This covering of the nerve endings in the cornea could contribute to the reduction of the postoperative pain.

The cost of one double syringe of Tisseel Duo Quick $(0.5 \mathrm{ml})$ is about equal to the cost of five sutures. Typically, we operate on six to seven patients on one day with the same Tisseel syringes, although those would be enough for eight to nine patients. Thus, the material cost of the cut and paste method became somewhat lower than that of the sutures. In addition, the time cost is about the half of that with sutures.

Thus, the presence of the sutures causes significantly more postoperative pain. This may be due to the sutures themselves and/or the inflammatory process around the sutures during degradation. ${ }^{21}$

The immediate adhesion of the whole graft may inhibit the fibroblasts of the nasal Tenon's tissue from proliferating towards the cornea, keeping recurrence rate low.

Prospective series in the literature report 2\%-39\% recurrence rate. ${ }^{22}$ The total recurrence rate in this study is $14 \%$. All six recurrences in our study were small; no reoperations were required. The two recurrences in the glue group started at the inferior graft corners; the cause could be inadequate excision of the pterygium tissue or perhaps too much Tenon's tissue left on the graft. Using fibrin glue for graft fixation in pterygium surgery is a safe, fast method and does not have any side effects. The recurrence rate seems not to be higher than that with sutures. The total discomfort is considerably less. Further evaluation of the recurrence rate is needed with larger series. Based on these results we recommend early intervention, thus shortening the suffering time for these patients and also keeping postoperative astigmatism and postoperative corneal haze to a minimum.

\section{Authors' affiliations}

G Koranyi, S Seregard, E D Kopp, St Erik's Eye Hospital, Karolinska Institutet, Stockholm, Sweden

\section{REFERENCES}

1 Moran DJ, Hollows FC. Pterygium and ultraviolet radiation: a positive correlation. Br J Ophthalmol 1984;68:343-6.

2 Nakaishi $\mathbf{H}$, Yamamoto $M$, Ishida $M$, et al. Pingueculae and pterygia in motorcycle policemen. Ind Health 1997;35:325-9.

3 Norn M, Franck C. Long-term changes in the outer part of the eye in welders. Prevalence of spheroid degeneration, pinguecula, pterygium, and corneal cicatrices. Acta Ophthalmol (Copenh) 1991;69:382-6.

4 Booth F. Heredity in one hundred patients admitted for excision of pterygia. Aust N Z J Ophthalmol 1985;13:59-61.

5 Tsubota K. Application of erbium:YAG laser in ocular ablation. Ophthalmologica 1990;200:117-22.

6 Seiler T, Schnelle B, Wollensak J. Pterygium excision using 193-nm excimer laser smoothing and topical mitomycin C. Ger J Ophthalmol 1992;1:429-31.

7 Kenyon KR, Wagoner MD, Hettinger ME. Conjunctival autograft transplantation for advanced and recurrent pterygium. Ophthalmology 1985;92:1461-70.

8 Chen PP, Ariyasu RG, Kaza V, et al. A randomized trial comparing mitomycin $\mathrm{C}$ and conjunctival autograft after excision of primary pterygium [see comments]. Am J Ophthalmol 1995;120:151-60.

9 Prabhasawat P, Barton K, Burkett G, et al. Comparison of conjunctival autografts, amniotic membrane grafts, and primary closure for pterygium excision. Ophthalmology 1997; 104:974-85.

10 Hirst LW, Sebban A, Chant D. Pterygium recurrence time. Ophthalmology 1994; 101:755-8

11 Redl H, Schlag G. Fibrin sealant and its modes of application. In: Schlag G, Redl H, eds. Fibrin sealant in operative medicine, Vol 2. Ophthalmology, neurosurgery. Berlin, Heidelberg: Springer Verlag, 1986:13-25.

12 Schlag G, Aschler PW, Steinkogler FJ, et al. Fibrin sealing in surgical and nonsurgical fields, Vol'5. Neurosurgery, ophthalmic surgery, ENT. Berlin, Heidelberg, New York: Springer Verlag, 1994

13 Schlag G, Redl H. Fibrin Sealant in Operative Medicine, Vol 2. Ophthalmology, neurosurgery. Berlin, Heidelberg: Springer Verlag, 1986.

14 Buschmann W, Mester U. Fibrinklebung in der Ophthalmochirurgie. Stuttgart: Ferdinand Enke Verlag, 1995.

15 Cohen RA, McDonald MB. Fixation of conjunctival autografts with an organic tissue adhesive [letter]. Arch Ophthalmol 1993;111:1167-8.

16 Wishaw K, Billington D, O'Brien D, et al. The use of orbital morphine for postoperative analgesia in pterygium surgery. Anaesth Intensive Care 2000;28:43-5.

17 Shaw EL. A modified technique for conjunctival transplant. CLAO J 1992; 18:112-6.

18 Leibowitz HM, Bartlett JD, Rich R, et al. Intraocular pressure-raising potential of $1.0 \%$ rimexolone in patients responding to corticosteroids. Arch Ophthalmol 1996;114:933-7.

19 Simona F, Tabatabay CA, Levenberger PM. [Lamellar corneal graft in the treatment of pterygium. A 10-year retrospective study of the recurrence and changes of astigmatism]. J Fr Ophtalmol 1988;11:759-63.

20 Snibson GR. An evidence-based appraisal of treatment options. In: Taylor HR, ed. Pterygium. The Hague: Kugler Publications, 2000:125-39.

21 Biedner B, Rosenthal G. Conjunctival closure in strabismus surgery: Vicryl versus fibrin glue. Ophthalmic Surg Lasers 1996;27:967.

22 Tan DTH, Chee SP, Dear KGB, et al. Effect of pterygium morphology on pterygium recurrence in a controlled trial comparing conjunctival autografting with bare sclera excision. Arch Ophthalmol 1997; 115:1235-40. 